\title{
Classroom Monitoring and Energy Conservation System by employing PIR Sensor
}

\author{
Kanika Jindal, Manish Kaushik, Amit Tripathi
}

\begin{abstract}
Present system relates to the designing of an energy conservation system that uses a Passive Infrared Radio sensor(PIR) for controlling light and fan when classroom is vacant. When anyone (human being) make an entry into the classroom, then the Infrared energy released by the human body is concentrated by a Fresnel lens section which triggers the 'PIR' sensors and the signal is transmitted to a microcontroller associated within the system. Once motion is sensed the relays comes into action and on the fan and light. The condition to turn on the operation fan is only the classroom reaches a value of temperature of 25 degree $C-30$ degree $C$.
\end{abstract}

Index Terms- Energy monitoring system, PIR sensor, Microcontroller, Fan, Light.

\section{INTRODUCTION}

In starting turning on/off of electrical devices has been carried out by connecting and disconnecting the devices from the electrical grid. Recently this method of switching become less popular and automation has been introduced in the system. By this it can be said that interior device is detached from the switching circuit. Today the electrical appliance can be operated by a single remote control.

Some of the computer main boards permit response to the power circuit events, in paper [1] it is discussed that the problem related to switching unit is absorbing power till it is in on state. It is explained in [6], that the governing the intensity of lights and speed of fans by using a single infrared remote controller in regular limit of frequency.

Passive Infra-Red sensor is generally used to identify the motion, the sensor does its work by observing variations in the heat levels (infrared) released by the different objects present in surrounding. A high signal is generated by the sensor on the output pin after the identification of motion. A microcontroller associated with the sensor receives the signal and then does its work of accordingly switching on the high voltage devices. For observation of motion this sensor is best in [1]. There are 2 revisions comprised by the sensor one is Revision A and another one is Revision B. Basic principle of these 2 revisions is similar, though some amendments have been done in Revision B disclosed in paper [2]. Controlling of speed of fan and illumination of light is done by the employment of a microcontroller. Linear outline has tracked

Revised Version Manuscript Received on 10 September, 2019.

Kanika Jindal,Department of Electronics \& Communication Engineering, Noida Institute of Engineering and Technology, UttarPradesh, India. (Email: researchnietip@gmail.com)

Dr. Manish Kaushik, Department of Chemistry, Noida Institute of Engineering and Technology, UttarPradesh, India. (Email: researchnietip@gmail.com)

Amit Tripathi, Department of Electrical \& Electronics Engineering, Noida Institute of Engineering and Technology, UttarPradesh, India. (Email: researchnietip@gmail.com)

by the system and monitoring is achieved. In paper [2], simulation of a mathematical model is done for controlling AC system with the help of 'Matlab Simulink' software relied on adaptive 'fuzzy control' and then followed by the observation of the result and performance of fuzzy logic controller.

It is projected in paper [3] that by the use of a LDR sensor which consists of a circuit for turning off operation for the luminance device in the presence of sufficient day light and turning on when the sufficient natural light is not present. The designing of a system which concentrates on security has been developed in paper [7], for this a system that alerts the person when someone is passing by generating an alarm. The implication of designing this, was turning on and off electrical lights automatically as a result power conservation is done. The improvement in this system can be done by combining the system with a new timing system.

Authors have explained in paper [4], the study inspected an electronic circuit that used a PIR sensor for developing a motion identifier. With the association of microcontroller and an LCD display, a message is displayed like "motion detected". When there are increased ports of microcontroller the system can also be appropriate for many loads such as pressure and force etc.. The proposed system can also be employed for reducing power wastage of electricity. By employing a delay timer unit with the system, the system can be modified for indoor lamps. It was examined in paper [8], everyday electricity absorption with the help of LCD and GSM to alert absorption. The software called 'Keil ( $\mu$ vision IDE) and Micro Flash used to accomplish the decrease in intensity of light based on user preference and therefore resulting in energy controlling. A comfortable home management system is obtained by the PIR sensors and the ARM. This system could also identify the faulty appliances resulting in more power consumption.

Remote controller regulating a fan has been designed and executed in paper [9]. In paper [5], a Proportional study on consumption of energy for wireless sensor networks which was related to random and grid distribution approaches was conveyed.

The rest parts of this paper is organized as: The following part of this paper is part II, represents the Methodology of the system. III part is testing and calibration of device. Conclusion is fourth part of the paper that completes the presented paper by telling future directions. 


\section{Classroom Monitoring and Energy Conservation System by employing PIR Sensor}

\section{METHODOLOGY}

The connection of various modules is shown in the Figure 1.

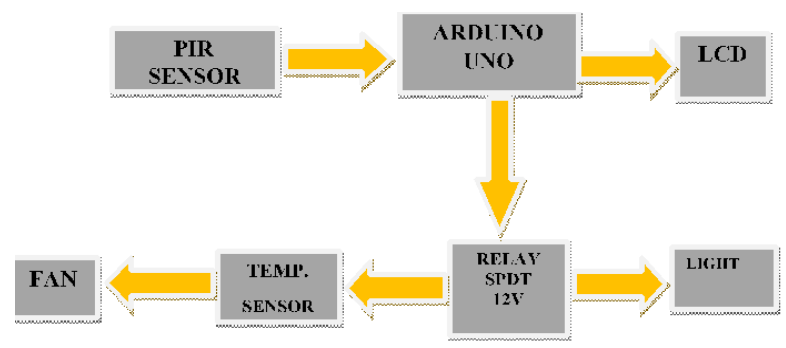

Figure 1 Block diagram of system

The system includes many modules that are used in building of system. Pins (Output, Input and Gnd) of PIR sensor are linked to the microcontroller which is preferably an arduino UNO [10] via a bread board connection. The power consuming loads i.e. fan and lamp are also attached to the bread board, a temperature sensing senor is used in the system and is coupled to the fan. The sensor has been situated in the classroom for covering the whole area.

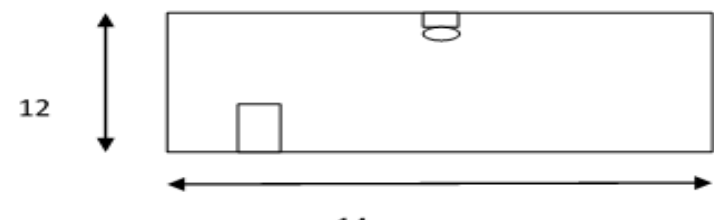

14

Figure 2 Schematic Diagram

The 2nd thought was relied upon Fresnel zone therefore all the sensors have been positioned above the loads (fan and the lamp) therefore the sensors are able in identifying motion in the classroom for switching loads (fan or lamp) off automatically. Area which has been considered for the project is a classroom of specifications $12 \mathrm{mX} 14 \mathrm{~m}$, area view and PIR sensor is shown in Figure 2. In order to implement the designing, 'Windows operating system (windows 7)' and 'EGLE cad' software have been used. Specifications for arduino is mentioned in Table 1.

Table 1: Specifications of microcontroller

\begin{tabular}{|c|c|}
\hline DISCRIPTION & SPECIFICATION \\
\hline Microcontroller & ATmega328P \\
\hline Operating Voltage & $5 \mathrm{~V}$ \\
\hline $\begin{array}{l}\text { Input Voltage } \\
\text { (recommended) }\end{array}$ & $7-12 \mathrm{~V}$ \\
\hline Input Voltage (limit) & $6-20 \mathrm{~V}$ \\
\hline Digital I/O Pins & $\begin{array}{l}14 \text { (of which } 6 \text { provide } \\
\text { PWM output }\end{array}$ \\
\hline PWM Digital I/O Pin & 6 \\
\hline Analog Input Pins & 6 \\
\hline $\begin{array}{l}\text { DC Current per I/O } \\
\text { Pin }\end{array}$ & $20 \mathrm{~mA}$ \\
\hline $\begin{array}{l}\text { DC Current for } 3.3 \mathrm{~V} \\
\text { Pin }\end{array}$ & $50 \mathrm{~mA}$ \\
\hline Flash Memory & $\begin{array}{l}32 \mathrm{~Kb} \text { (ATmega32P) of } \\
\text { which } 0.5 \mathrm{kB} \text { used by } \\
\text { bootloader }\end{array}$ \\
\hline SRAM & 2Kb (ATmega328P) \\
\hline EEPROM & $1 \mathrm{~Kb}$ (ATmega328P) \\
\hline Clock Speed & $16 \mathrm{MHz}$ \\
\hline Length & $68.6 \mathrm{~mm}$ \\
\hline Width & $53.4 \mathrm{~mm}$ \\
\hline Weight & $25 \mathrm{~g}$ \\
\hline
\end{tabular}

If the area is vacant then lamp load is kept off else they get on automatically. Switch of the fan gets 'on' if and only if the room temperature exists in a range of.

\section{TESTING AND CALIBRATION\& RESULTS}

In the section of testing and calibration, the system has a voltmeter and an ammeter. For this the system is connected to the power supply after that following constraints have been verified: Total power consumed is obtained by the multiplication of calculated voltage and calculated current. The minimum value and maximum value of the voltage and the current have been noted and calculated the consumed power is given as follows:

Table 2 Measured values of voltage current and power

\begin{tabular}{|c|c|c|}
\hline Voltage (V) & Current (mA) & Power (mW) \\
\hline 7 & 87 & 609 \\
\hline 9 & 100 & 900 \\
\hline 12 & 120 & 1440 \\
\hline
\end{tabular}

The system is relatively unbalanced and made the resetting of microcontroller while it's power-droved of seven volts source power. When nine volt source power is used then it would run the system effortlessly without malfunctioning and the current is effective for the operation. By the $12 \mathrm{~V}$ supply power arduino type micro-controller gets heated up. Because the microcontroller is associated with a voltage regulator IC whose maximum input is $7 \mathrm{~V}$. Though the technical specification declares that maximum of $18 \mathrm{~V}$ can be handled but due to heating inefficient power usage happens. After all taking all the considerations in mind it is decided that $9 \mathrm{~V}$ supply power is better option according to its availability and less power consumption. The view angle test and range test have been done to observe the system view area. The system is fixed on the top of a room with the dimensions of $10 \mathrm{~m} \times 5$ $\mathrm{m} \times 4.5 \mathrm{~m}$. The system can identify the existence of a person just at the entrance of the room and also at the end of the room. The system helps in doing on and off operation of light according to the presence of human being and on the fan when temperature value exceeds value of 30 degrees.

For testing the sensitivity of the system, the system is placed inside the room and 3 persons are involved in an intangible action in the room. It is observed that the system is working and turned on the light till the persons are present in the room and after going out of the room, the system has turned off the lighting lamp in ten seconds, precisely as the programming is loaded in it. For testing temperature the system has been positioned near to an incandescent type bulb fixed in the room. Threshold temperature value has been set between 25 degree C- 30 degree C. A standing type fan was installed at the system's fan output. It is observed that fan starts functioning when the temperature value rises to 25 degree $\mathrm{C}$. The fan stops functioning when the temperature falls below 20 degree $\mathrm{C}$ which is the minimum value of temperature set in the programming of the system.

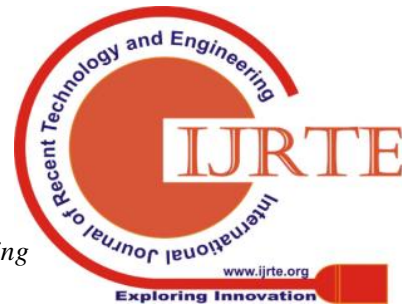




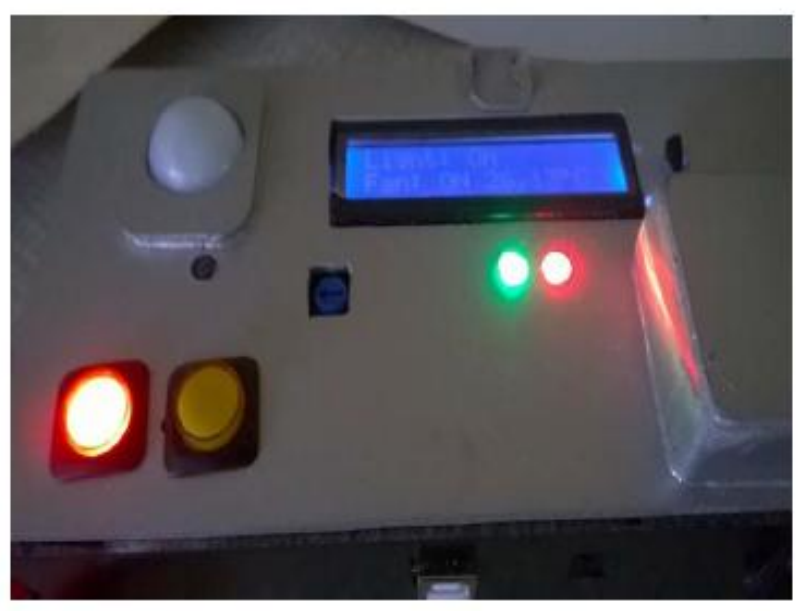

Figure 3 View angle and range test result

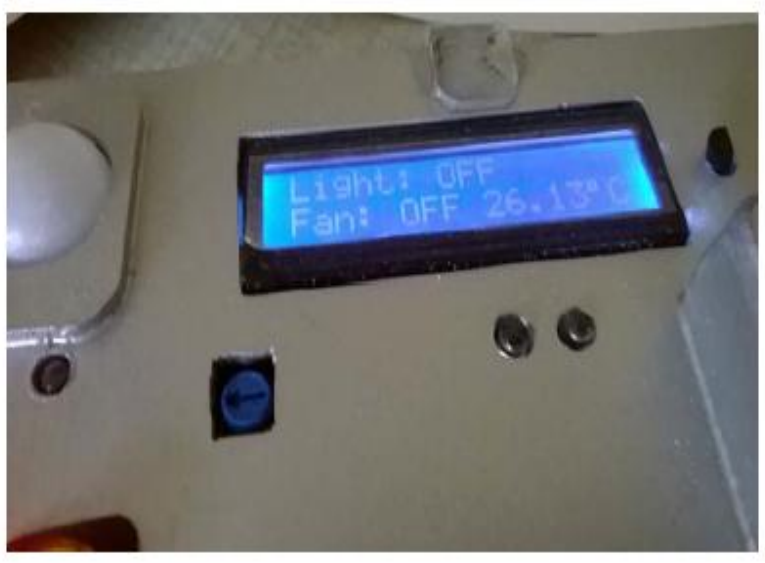

Figure 4 Device before test

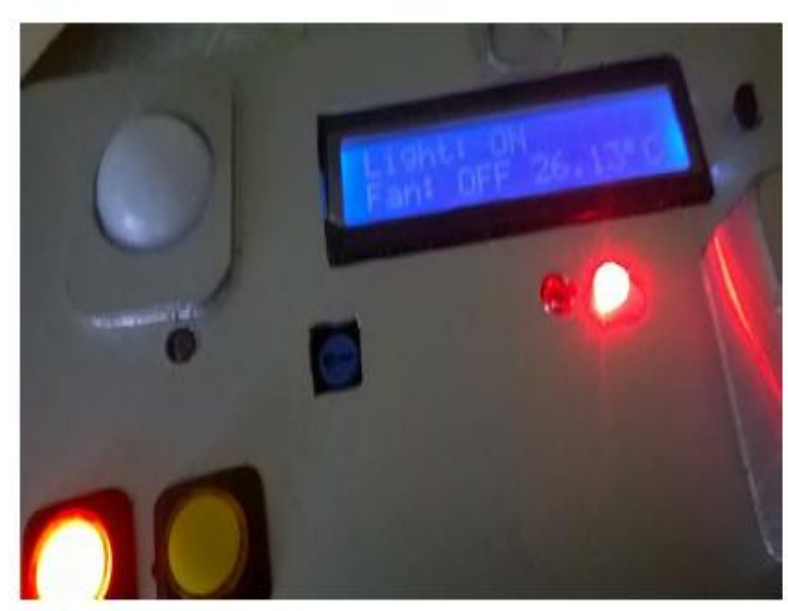

Figure 5 System during test

\section{CONCLUSION}

The presented paper explains about an energy conservation system in which a PIR sensor for switching on/off operation of the illumination light and fan of the classroom when students are not present in the room and system has been placed at the entrance of the room. The sensitivity limit was low by this placement, therefore a $2^{\text {nd }}$ unit was positioned diagonally at the far end to recover the limit of sensitivity. System includes a motion indicator sensor and temperature sensing sensor. The work of the motion indicator sensor is to sense any displacement in the room via IR heat produced by the body of a human being.

The senor for temperature work when the value of temperature exceeds its threshold value. For the project the temperature range which has been specified is 25-30 degree centigrade. 2 sensor are used in the system and positioning of them is diagonally. So by the implementation of the project energy wastage is reduced up to a limit.

\section{REFERENCES}

1. E. Adetiba, V. O. Matthews, A. A. Awelewa, I. A Samuel, and J. A. Badejo, "Automatic Electrical Appliances Control Panel Based on Infrared and Wi-Fi: A Framework for Electrical Energy Conservation,” Int. J. Sci. Eng. Res., 2011.

2. A. A. Adelakun, A. Adeyinka, A. A. Abdulkareem, and J. O. Olowoleni, "Automatic Control and Monitoring of Electrical Energy Consumption Using PIR Sensor Module,” Int. J. Sci. Eng. Res., 2014.

3. A. A. A, I. Samuel, A. A. A, and D. U. Ike, "Design and Development of a Microcontroller Based Automatic Switch for Home Appliances," Int. J. Eng. Sci. Invent ISSN (Online, 2013.

4. K. Sravani, P. Ahmed, N. C. Sekhar, G. Sirisha, and V. Prasad, "Human Motion Detection Using Passive Infra Red Sensor," Int. J. Res. Comput. Appl. Inf. Technol., 2014.

5. M. Monica and A. K. Sharma, "Comparative Study of Energy Consumption for Wireless Sensor Networks based on Random and Grid Deployment Strategies," Int. J. Comput. Appl., 2010.

6. Liji and e. al., "control of electrical lights and fans using Tv remote.," 2005.

7. S. Prasanna and e. al., "Automated Intelligent Power Saving System and Security System," Research India Publications, pp. 1167-1176, 2013.

8. K. K. Lunawat and U. M. Gokhale, "Home appliances control and energy management using PIR Sensor and ARM Processor," Advance research in Electronics \& Communication Engineering, 2015.

9. M. Samiran and K. N. Pabitra, "IR Remote signal control decoder for home automation," Engineering Sciences and Innovative Technology, pp. 262-267, 2014.

10. "www.arduino store community and electronics.htm," [Online]. Available: http://www.arduino store community and electronics.htm. [Accessed 21 June 2016]. 